J. Environ. Sci. \& Natural Resources, 7(1): 281- 288, 2014

ISSN 1999-7361

\title{
Need for Conservation and Relocate the Historical Building - Sylhet, Bangladesh
}

\section{M. Rahman}

Department of Architecture

Shahjalal University of Science and Technology, Sylhet-3114, Bangladesh

Abstract: During British period many colonial style building were built in Sylhet and after that in later colonial period some building were furthermore build which followed that colonial style and later colonial style. Present Customs and Food Division Head Quarter (CFDHQ) building situated near Zindabazar, Sylhet; is one of them. Other than without proper conservation and mismanagements of proper authority this historical building lost its all archetype and the past heritage. Therefore this paper attempt to focus the importance and crisis of such kind of builds form and makes a case for historical conservation of this Customs and Food Division Head Quarter (CFDHQ), Sylhet. Again it tries to indentify the original history of this building, disclose the findings and discuss the appropriate ways or recommendations by proposing recovered layout plan to conserve and maintain and why existing function of this building should relocated and protect his building based on several proposal.

Key words: Conservation, Preservation, Relocate, Historical Conservation, Arche

\section{Introduction}

Though conservation and preservation of old building is one of the recent program concerning the built environment of Bangladesh, it is realized that these buildings have important significance with the nation's historical development Nevertheless, most of the problems emerge the post colonial period where building $p$ and maintenance managements is emphasized in any conservation law and guidelines and by organization or parties that are respo for the upkeep of the buildings. These give a great impact to the buildings perform condition, structure character. Thus the and safeguard t with unswerving respect aesthetic historical and physical in
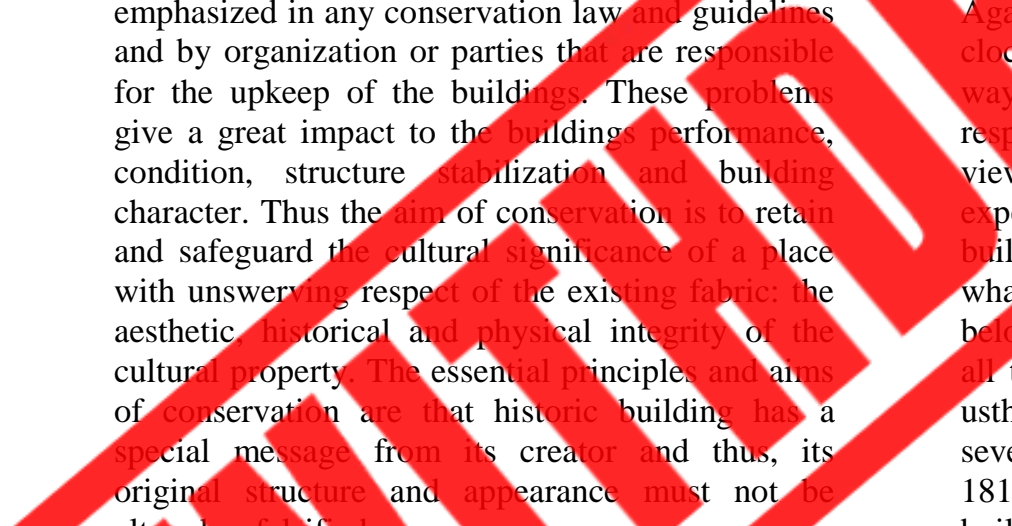

gaim Conservation is not about turning back the matter, but in reality it is a
funds required for
(Shan architectural heritage
not in the name of
not about turning back the ay to aligh the past and present to make way for responsible urban living with an improved future in view (Mustafa Zaman). Stillit is no question of xpedience or feeling whether we shall preserve the buildings past time or not. We have no right whatever to touch them. They are not ours. They belongs partly to those who built them and partly to 11 the generations of mankind who are to follow usthe greatest glory of a building is its age (the seven lamps of architecture-1849; Jhon Ruskin, 1819-1900). Once more the importance of old buildings not only on its function as it was on the past, but also gives us the picture of the lifestyle of the past generation. It also contributes to us the character of our past architectural heritage (Konrad, 1990; Choon, 1989). While to conserve a project historical remuneration has to be inquired. A deliberation is rendered over the particular historical carefulness of the project. In these points present CFDHQ is a valuable part of our past and that's why it should be sustained for the present and also for the future. Though our traditional culture changed for sometimes during British colonial period, but we should not cut off from our main stream and we should move forward because conservation of past heritage is not a stiff thing. Therefore the assessment itself to conserve is a dominant consequence and for the importance of the picture of the lifestyle and heritage of the past generation CFDHQ is obviously something admirable of conservation. 


\section{Conservation plan and process}

Conservation is about the care and continuing development of a place in such a waythat its significance is retained or revealed and its future is made secure.To enable that the significance of a historic place is to be retained, the process andapproach to conservation projects according to Mr. J.S. Kerr is summarized in thefollowing figure is very important in building conservation projects.All kind of expertise demands a high degree of cooperation, teamwork, experience, communication and knowledge of building materials and construction especially when dealing with this kind of historic buildings. Thus before the commencement of proposed conservation work, the methodology of overall process was designed first.

\section{Process on Conservation}

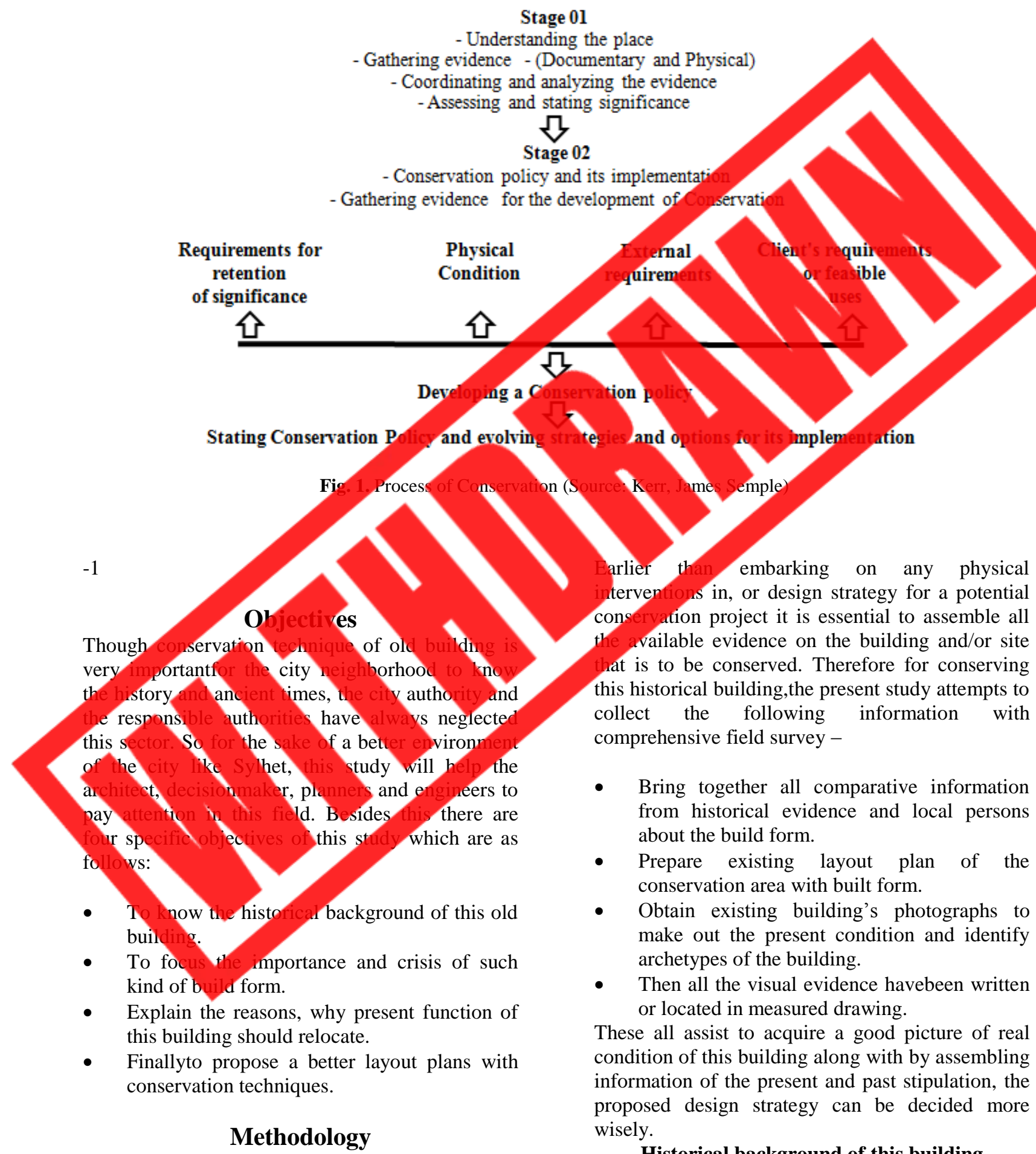

The framework of building research methodology 
Sylhet is a major city in north-eastern Bangladesh. It is the main city of Sylhet Division and Sylhet District, and was granted metropolitan city status in March 2009. In addition it is one of the largest cities in Bangladesh. It is located on the banks of the Surma River and is surrounded by the Jaintia, Khasi and Tripura hills. The city is approaching a population of 500,000 people while also having a high population density. Sylhet is well known for its culture and heritage. It has a long history of British Colonial period. History stated the 17th century started the British rule in the Indian subcontinent. During the period the British East India Company employed Indian lascars which included Sylhetis. In the late 18th century, the British East India Company became interested in Sylhet and saw it as an area of strategic importance in the war against Burma. Then Sylhet was gradually absorbed into British control and administration and was governed as a part of Bengal. During this episode many colonial style building were built in Sylhet and after that in later colonial period several building were furthermore build which followed that colonial style and later colonial style. Present Customs and Food Division Head Quarter (CFDHQ) building situated Zindabazar, Sylhet; is one of them. However history says CFDHQ building was built for residential purpose and the owney of thi building was Roy BahadurGirish $C$ was the first Engineer of Sy appointed as first chief municipality was found in the year of 1878 .He made his graduation on civil eng Shibpur Engineering Collage Kolka (internet search will need).He worke British Martin company in Kolkata; appo an engineer for "Paypur city extension project,
India" and also worked inthe variots famous
architectural projects. Thus the existing different
architectural motifs of this building express the
knowledge of his experience and design
techniques. Then duking separation of India and Pakistan in 1947 the ownership was sold to DewanEklimur Raja (Son of Hasan Raja), because in that period Girish Chandra Dash yas migrated to Kolkata from Sylhet. After three years in 1950 Government took requisition of the building and established it with new function as Customs and Food Division Head Quarter (CFDHQ)in the same period. Subsequently the complex is contentiously being used as a Customs and Food Division Head quarter, Sylhet. Starting asa government office building to till now, few renovations were rendered over the complex for functional purpose that snatched away the original appearance of the complex.In addition history ejected from the existing build form is enough then a text reference as there is not muchwritten evidence inany books about this building. Any source of any information about this build form is still rare. Physical survey and discussion with some local person managed to accumulatesome historic essence about this build form.

In addition these evidences explain the engraved year on the pediment which surmises that it took eight years to construct the mainbuilding of the complex. These evidences also illustratesthat the north wing of the building established in 1926 and pediment of the east wing says it was constructed within year, 1928; later the south wing of the building was composed with north and east wing in the year, 1934.The portion built around the courtyard now being used as the residence of the guard, is assumed to be built at the same period of the east wing; cause the exploration of the east wingand the guard room has proven to be same. The colonnade space does have some dispute about building period, the purpose of also has wavering opinion, survey map of 1956

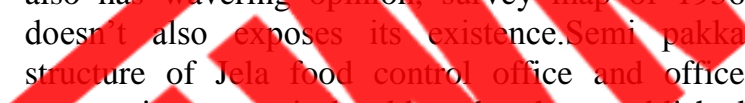

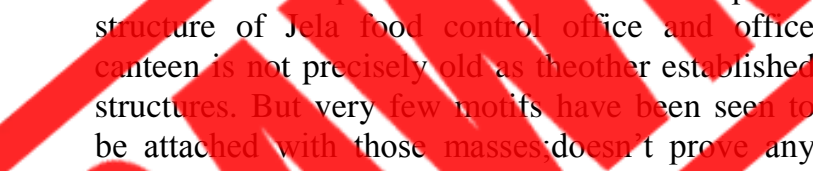
be attached with those masses doesurt prove any historical importance of those building. The mosque built in 1975 and reneyated in 2004, do not
have any eventful background. Exploration of the Ghat(seating area) similarize with the trite
ornamentation of the main burlding, whilesudden use of detailed ornamentation in the sitting raises importance. Proof of the waterbody erected ing the built period of the main building can be ssumed through properobservation.Subsequent figure 2 shows the existing condition of build form
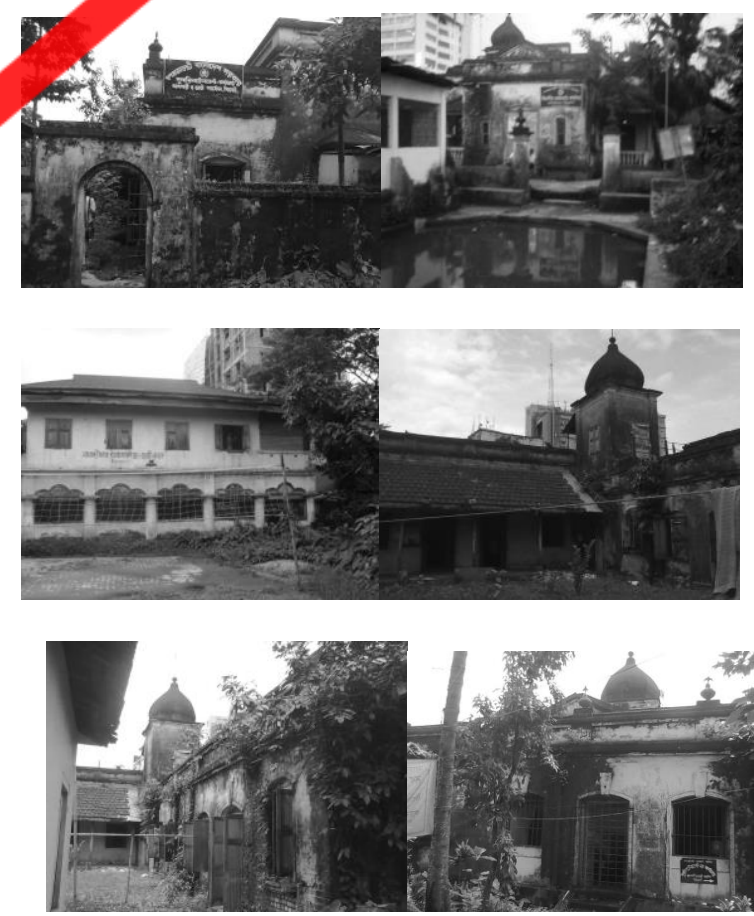

Fig. 2.Existing build form and Views of the site 


\section{Built form \& functional arrangement of present CFDHQ building}

"Customs and Food Division Head quarter" is situated in between Zindabazar and Chowhatta, the centre of commercial activity within Sylhet city. Total area of the site is approximately - 1 , 92,550sqft.Among it shaded area is 96,275sqft, open area is 83,008 sqft and water body is 13,267 sqft. Next figure 3 shows the exact location of this site and the surroundings.

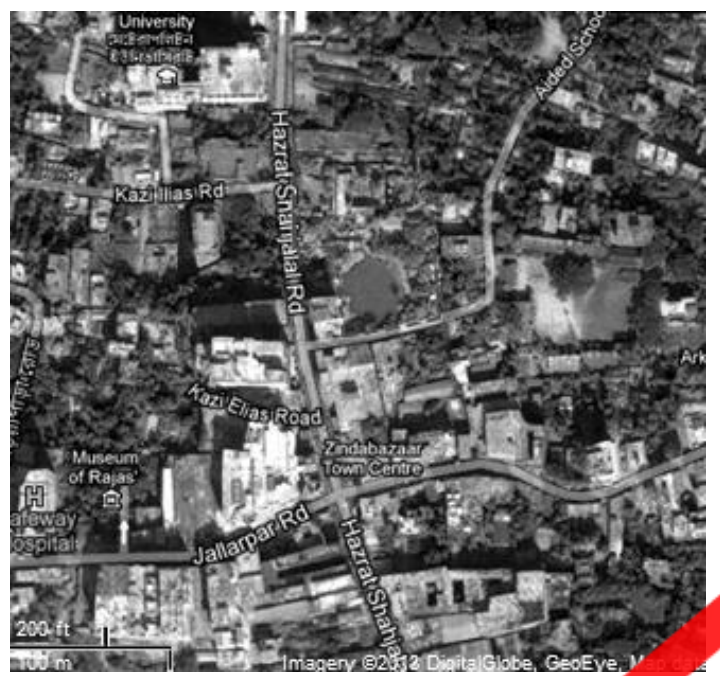

Fig. 3. Location of CFDHQ build
The present functional arrangements of CFDHQ show that total number of build form is nine. Figure 4 exhibits the existing plan and functional arrangements of the site. It shows that the mainbuildingin this site is Customs and Food Department office. Afterward the two storied colonnade space in this site now using as a club building, few clerks temporally live in upper slab of this building. In front of the club building there is a tennis court. Other two buildings around the courtyard are being used to accommodate the guards. Walls are constructed nearby the guard room defining the garden and to define the boundary wall of water body. The Ghat(seating area) besides the water body was decorated with Kioskand exclusive treatment.In front of the main building a deferent portion of Food Control office is locatedwith a semi PakkaGhar and just at the opposite of the main entry; beside the pond a new mosque is located. A canteen with minimum service only for official persons is in front of the mosque. The other two temporary structures which are located to the east side besides of the pond ar less important to point out and there is anothe entry from Tatibazar road which has totally west and south elevation of this CFDHQ building cor 
triangular shape with sunken panels of decoration.

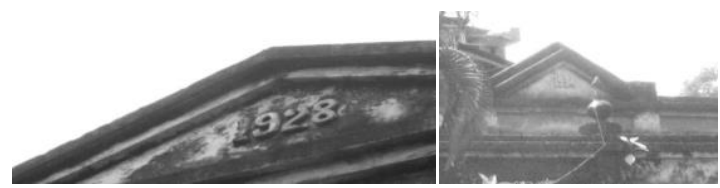

Fig. 8.Pediment

- It has also masonry skewback against sloping face.

Enclosure entry:

- Total number of enclosure entry in this complex is four.

- Every enclosure entry has archivolt which is stilted and has three concentric masonry rings

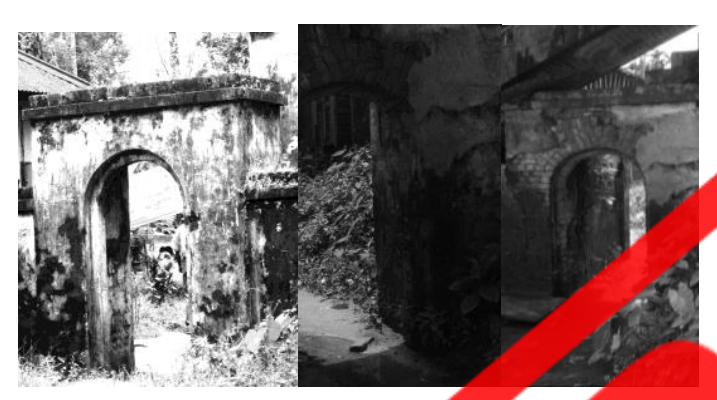

Fig. 9.Enclosure Entry

formingorder; below.

- The entry

Then two slantwi and encompassed

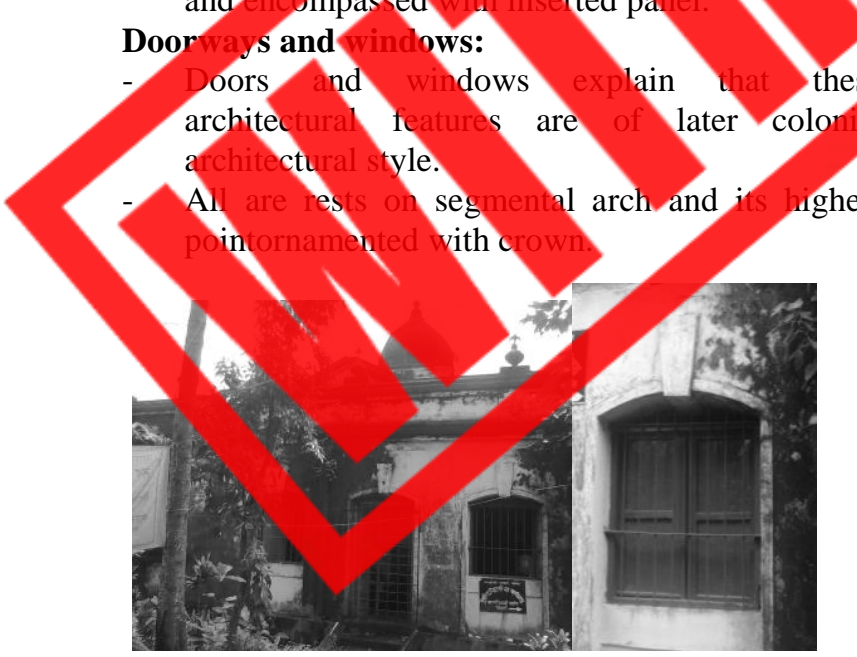

- In entry level it display Elizabethan Pattern of doorway.

- Then in main entry level there is few slender pointed arched lancet windows.

Dome:

- Onion style ofdome were used whichhas light belfry structure.

- The top of every domeconsist flag rail with vaulted base.

- The base of dome has projecting slab like corona of cornice and strap bandage placed around springing of dome and base of the dome is square form.

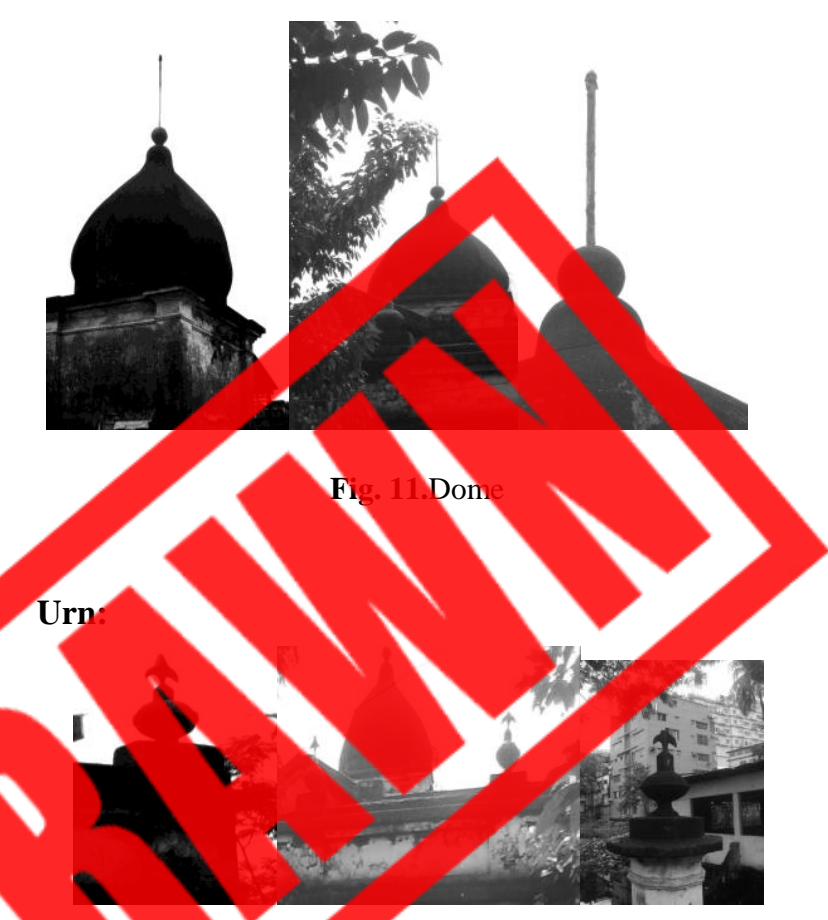




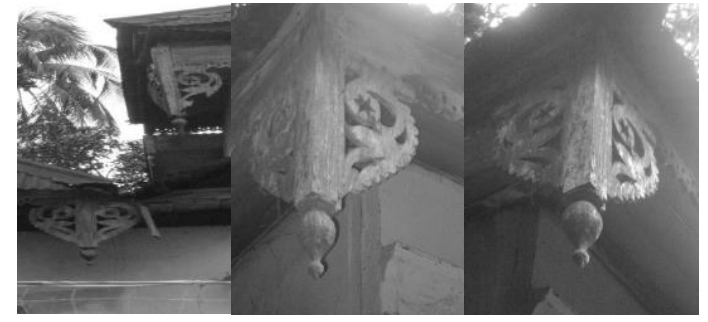

\section{Balustrade:}

- Use of balustrade in every stair and veranda as railing.

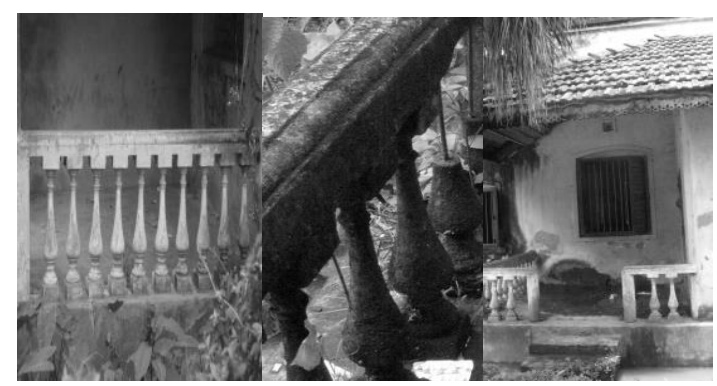

Fig. 15.Balustrade

- Every balustrade has short stems with abaci

- Also has one bulb with rings shape.

- Oval and cavetto moldings with post and column Column like balustrade are found.
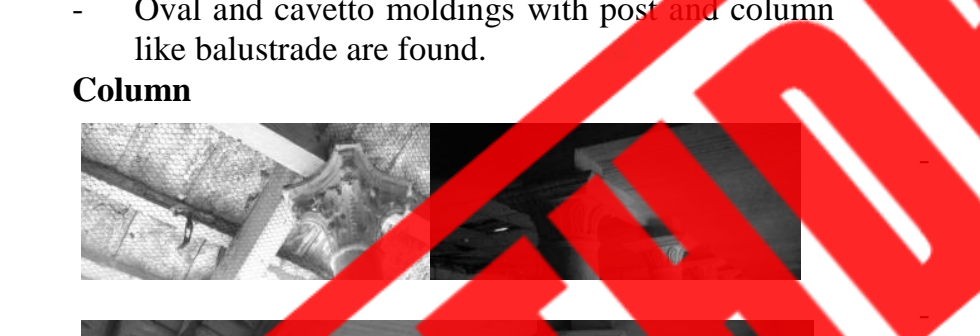

\section{Proposals and Recommendation}

The overall condition of this site is very congested and the present situation of this building is not so sound, whereas this area is very much busy and important location for urban neighborhood as a variety of reasons. On the other hand this complex has very significant value to know our history. Therefore planning and design proposals areproposed with a view of conserving the urban character of this area and the building itself with a open space for break of urban dwellers. In addition enhancing its quality by providing walkway and landscaping to feel the history and as a final point introducing some breathing space is proposed for the best use of this site. Besides these for conserving this historical building, this study also proposed following proposals and recommendations

\section{- Initially confirmed this site as} area. So when

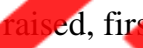
with histor

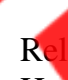
Relocate present $\mathrm{C}$
Head Qtarter to oth

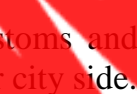
impor

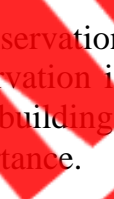

Then apply the existing buriding as a museum demonstrate Roy BahadurGirish Chandra as, who was very amous engineering in this eason and exhibit his pastexistence.

Then this study proposed four steps of planning and designing process for implementing the final layout plan.

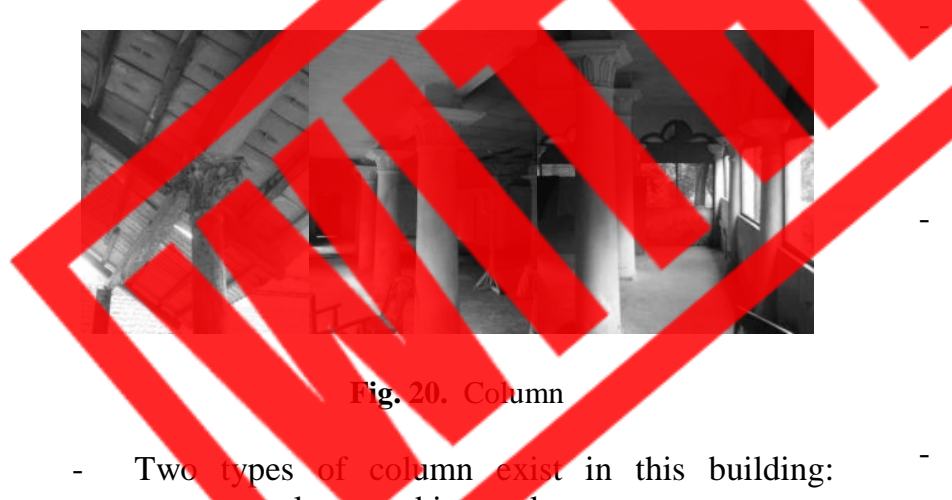
concrete column and iron columns.

- The architrave of colymns resembles Corinthian order and the entasis shaft resembles the Tuscan.

- Bell features acanthus, helix and caulicles and it precisely resembles with Corinthian order.

- Presence of hypotrachelium and prominent three echinus moldings with pointed trefoil arch in drop and has only plinth in base.

- Iron columns having slender shaft and the capital stylized of crocket.
In step 01, rearrange some existing structure, such as - Moshjid, Canteen and Guard Room and remove all temporary structure as proposed plan.

Step 02; develop the bank of pond as anopen area and developed for landscaping and walking area. This could be done by restricting vehicular entry and arrangement seating and necessary landscaping.

- This step also required to developthe east side colloned platform area by removing present tennis court and other temporary structure as performing playful activities.

- Step o3; when every temporary structure removed from the site, this study then proposed a walkway around the entire site.

- Step o4; later than completing the previous plan, repair the whole structure as it was with the help of proper authority and experience persons. 
Finally improve of the service of all the buildings to a satisfactory standard as it was. This will involved the development of drainage, sewerage, water supply, gas, electricity and walkway lighting.
This building does not reflect as a government building and not supporting enough storage for the function

- Ergonomically this building is not suited for an office activity,for this reason furniture cannot

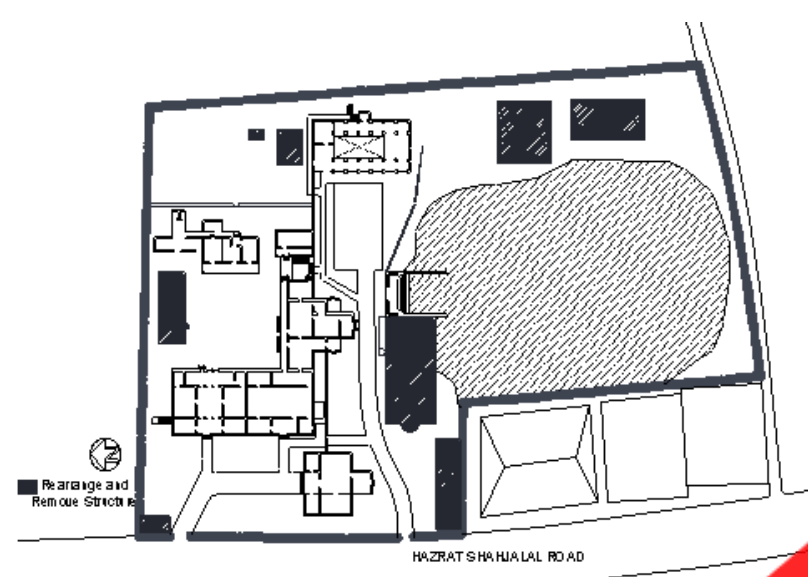

Fig. 21.Proposed plan_step 1 (rearrange and re

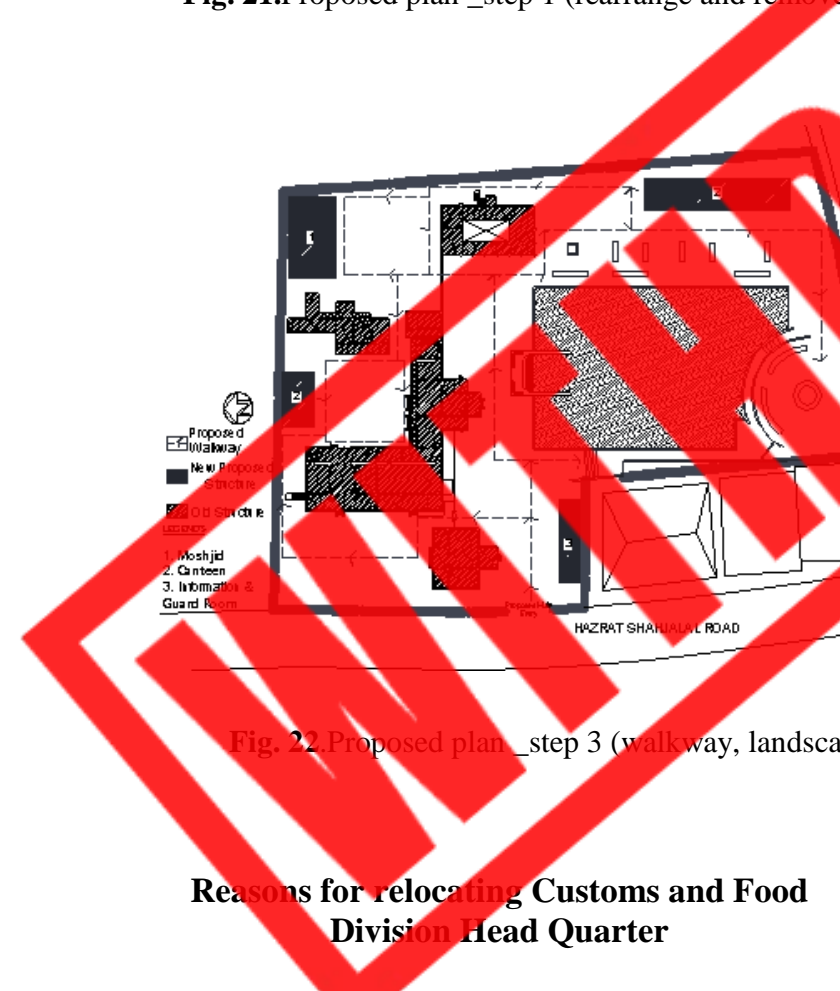

As history define this building was built for residential purpose and its functional arrangements reflects that it was a residential building, therefore present function "Customs and Food Division Head quarter" office should relocate in suitable space. Once more subsequent are some reasons for relocating this office -

- No facilities to accomplish administrative purpose and no executive establishment, meeting room, supervision office, waiting and reception area in this building. locate properly.

- Presently life safeties of all employers are threatening for the building's poor structural condition and the heavy vehicular access around the building causing wane of durability.

- Afterwards most of the Custom's Office administrative activities take place in Upashahar, (Sylhel) new office, only few administrative activities taking place in this site.

- The surrounding circumstance of this commercial zone is also not suitable for acustoms house. Because Sylhet city's major administrative center is in Bandar Bazar area 
where government offices like - D.C. office, G.P.O. Circuit house, Judge Court, City Corporation are located. So that area is more suitable for present Customs and Food Division Head Quarter and should be allocated on that area.

\section{Conclusion}

Building conservation requires particular planning, expertise, care and execution because historicmonuments are significant and invaluable heritage of our culture that once lost ordamaged cannot be replaced. Therefore conservation of historic buildings and cultural properties is about authenticity and theprinciples governing conservation have taken centuries of philosophical, aesthetic andtechnical progress to articulate. In addition if viewed from the wider context,the risin land value and crisis in the urban areas historical buildings are now re-used. Of cov very difficult to start protecting historic building in a city where market forces and land crisis have always determined the pattern of a building is threatened when is greater than the value since building is adopt hand the Customs a Building (CFDHQ), a symbol of the Britis colonial period, has lost its originality to some extent due to change its original fur unsystematic change of its function fro to administration building, has affected the

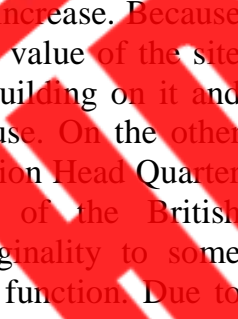
both aesthetically and structural is acutely related with the city history. In this circumst rity $\mathrm{t}$ ted the building the building becomes necessary ke a better policy to beco its gloriou. conserve the building with respect of its existing functions and condition.

\section{References}

A Pattern LanguageAjuthcharanTattanidhi; History of Sylhet

Bernard Fleture; Art and Architect

Christopher Alexander, Sara Ishifkawa, Murray Silverste

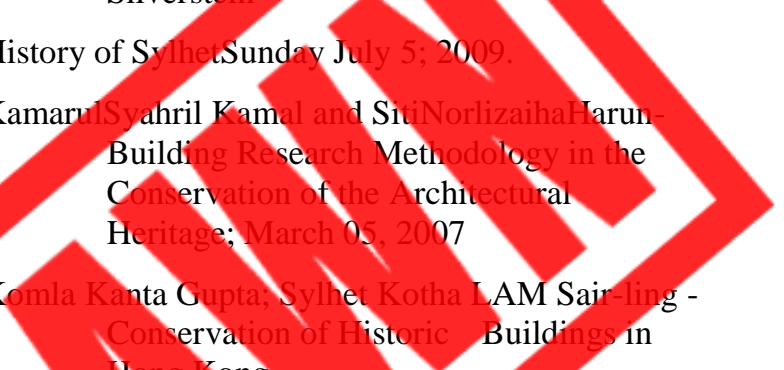

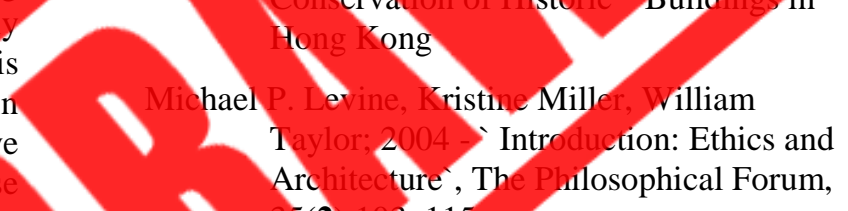

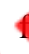

Sylhet at British Period Sunday, August 7, 2011 